\title{
Biology and management of mealybug, Paracoccus marginatus Williams and Granara de Willink on Jatropha curcas $L$.
}

\author{
Veeresh Kumar*, S. C. Topagi, B. S. Rajendra Prasad, Revanasidda, K. B. Tharini and \\ C. T. Ashok Kumar
}

Department of Entomology, University of Agricultural Sciences, GKVK, Bangalore (Karnataka), INDIA

*Corresponding author, E-mail: veeresh4279@gmail.com

Received: August 21, 2014; Revised received: November 15, 2014; Accepted: December 06, 2014

\begin{abstract}
Jatropha cultivation is gaining importance as potential source of biofuel. Recently Paracoccus marginatus has been found to cause serious damage on Jatropha. Studies on the biology and management of $P$. marginatus at GKVK, Bangalore revealed that the females had three nymphal instars without any pupal stage, while the male had three nymphal instars besides, pre-pupal and pupal stages. The total nymphal period for female ranged from 14 to 21 days, (mean- 17.32 \pm 1.6 days) while for male the range was 16 to 23 days, (mean- $18.9 \pm 1.3$ days). Bisexual and parthenogenetic modes of reproduction were observed. The fecundity of the female mealybug ranged from 248 to 967 , with an average of $618.9 \pm 19$ eggs. Evaluation of insecticides revealed that during first spray and second spray, mean per cent reduction of mealy bug population was highest in profenophos $0.05 \%$ (68.05 and 79.35$)$ followed by buprofezin $0.025 \%$ (63.61 and 72.69). Least per cent reduction of mealy bug was observed in the NSKE 5\% (17.94 and 25.77) treatment.
\end{abstract}

Keywords: Insecticides, Insect pests, Jatropha, Natural enemies, P. marginatus

\section{INTRODUCTION}

Biofuels are being promoted as sustainable alternatives to fossil fuels and the potential sources include jatropha, pongamia, mahua, neem, tumba, sal, jajoba and chullu. Among these Jatropha curcas L. (Euphorbiaceae) seems to be more promising, since the seeds are very rich in oil (40\%), which is used as biofuel (Dehgan, 1984; Pant et al., 2006). Although a native of Mexico and tropical America, it is being naturalized now throughout the world.

There are 22 species of insect and mite pests infesting jatropha of which papaya mealybug Paracoccus marginatus Williams and Granara de Willink causes severe damage (Veereshkumar and Ashok kumar, 2013). In India, the mealybug, $P$. marginatus was recorded in 2008 on papaya (Carica papaya L), mulberry (Morus spp.), jatropha (Jatropha curcus L.) and tapioca (Manihot esculenta Crantz), besides on some flower crops, vegetables and fruits (Regupathy and Ayyasamy, 2009; 2010; Mahalingam et al., 2010). More recently $P$. marginatus has been found to cause serious damage on jatropha. Initially the mealybugs, congregated on apical shoots and later covered the entire plant; both nymphs and adults are found to suck the sap from leaves, shoots and fruits. The infestation resulted in symptoms like crinkling or twisting of leaves and shoots, bunched and unopened leaves, yellowing of leaves or leaf drop, fruit drop, appearance of honey dew on leaves, sooty mould development, stunted growth, deformation and death of the plants in case of severe infestation (Meyerdirka et al., 2004; Lynne et al., 2005 ; Walker et al., 2008).

Since $P$. marginatus causes serious damage to jatropha, the present investigation was carried out to study the biology and to identify effective means of suppression of this pest on jatropha.

\section{MATERIALS AND METHODS}

Biology of $P$. marginatus was studied in the laboratory during 2011 at Gandhi Krishi Vigyan Kendra (GKVK), Bangalore. The mean maximum and minimum temperatures prevailed during the study were $28.5^{\circ} \mathrm{C}$ and $19.1^{\circ} \mathrm{C}$, respectively with mean relative humidity of 88.30 per cent. Terminal shoots of jatropha having cut ends were immersed into $250 \mathrm{ml}$ conical flask containing water to maintain the turgidity, placed in insect rearing cages $(35 \mathrm{~cm} \times 30 \mathrm{~cm} \times 35 \mathrm{~cm})$. Individual eggs were placed on the terminal shoots with a fine camel hair brush and totally twenty five replications were maintained. Observations were made twice in a day, on the incubation period, moulting period (to estimate the duration of each instar), total number of instars, pre pupa and pupa, pre oviposition, oviposition and post oviposition period, fecundity and adult longevity.

Efficacy of insecticide molecules and botanicals on $P$. marginatus was studied on jatropha seedlings raised in 
pots under glass house condition. The seedlings were artificially infested with 50 individuals of $P$. marginatus ( $2^{\text {nd }}$ and $3^{\text {rd }}$ instar nymphs) each. Three seedlings were maintained per treatment in each replication and the seedlings were kept at safe distances away to avoid drifting of the insecticides, while spraying.

The initial population of $P$. marginatus was recorded. The respective spray solution at the required concentration was prepared and $1 \mathrm{ml}$ of sticker was added to each litre of the suspension. The experiment was laid out in CRD, comprising of ten treatments, with three replications. The treatments were imposed by using a Ganesh hand sprayer. Observations were recorded both before spraying, two, five and ten days after spraying.

Observations were made on natural enemies of $P$. Marginatus at fortnight intervals. The percent parasitisation of major parasitoid was recorded and correlated with the weather parameters.

\section{RESULTS AND DISCUSSION}

Morphometrics and biology of $\boldsymbol{P}$. marginatus: The morphometric measurements on egg, nymphal instars, pupae and adults (both male and female) of $P$. marginatus on jatropha are shown in Table 1 . The growth parameters on developmental periods of egg, nymphal instars, pupae, adult (both male and female), pre-oviposition, oviposition, fecundity and post-oviposition period are shown in Table 2.

Studies on the biology of $P$. marginatus revealed that eggs are greenish yellow and are laid in an egg sac which is 3-4 times the body length and entirely covered with white wax. The incubation period varied from 3 to 9 days in female and 3 to 10 days in male. Similar biology observations were recorded by Miller and Miller (2002), Walker et al. (2008), Muniappan et al. (2008) and Singh and Beera (2010) who reported that the egg-laying of $P$. marginatus was usually in a small white ovi-sac and egg hatching occurred in about 10 days.

Female had three nymphal instars; the duration of first, second and third nymphal instars being 5.32, 3.48 and 8.52 days, respectively. The total developmental period of female nymphs ranged from 14 to 21 days, with a mean of 17.32 days. The present results are also in conformity with the findings of Muniappan et al.

Table 1. Morphometric measurements of different life stages of $P$. marginatus on Jatropha $\left({ }^{*} \mathrm{n}=10\right)$.

\begin{tabular}{|c|c|c|c|c|c|c|c|}
\hline \multirow{3}{*}{$\begin{array}{c}\text { S. } \\
\text { No. }\end{array}$} & \multirow{3}{*}{$\begin{array}{l}\text { Insect stages } \\
\text { Egg }\end{array}$} & \multicolumn{3}{|c|}{ Length(mm) } & \multicolumn{3}{|c|}{ Width(mm) } \\
\hline & & \multicolumn{2}{|c|}{ Range } & \multirow{2}{*}{$\frac{* \text { Mean } \pm \text { SD }}{0.35 \pm 0.01}$} & \multicolumn{2}{|c|}{ Range } & \multirow{2}{*}{$\frac{\text { Mean } \pm \text { SD }}{0.16 \pm 0.01}$} \\
\hline & & 0.32 & 0.37 & & 0.15 & 0.17 & \\
\hline \multicolumn{8}{|c|}{ Nymphs } \\
\hline 2 & $\mathrm{I}$ & 0.39 & 0.42 & $0.41 \pm 0.01$ & 0.19 & 0.21 & $0.19 \pm 0.01$ \\
\hline 3 & II & 0.48 & 0.59 & $0.55 \pm 0.03$ & 0.28 & 0.33 & $0.29 \pm 0.01$ \\
\hline 4 & III & 0.79 & 0.93 & $0.88 \pm 0.04$ & 0.52 & 0.61 & $0.57 \pm 0.03$ \\
\hline 5 & Pupa & 1.52 & 1.88 & $1.78 \pm 0.12$ & 0.42 & 0.62 & $0.05 \pm 0.06$ \\
\hline \multicolumn{8}{|c|}{ Adult } \\
\hline 6 & Female & 2.14 & 2.34 & $2.14 \pm 0.06$ & 1.12 & 1.29 & $1.21 \pm 0.05$ \\
\hline 7 & Male & 1.28 & 1.36 & $1.29 \pm 0.03$ & 0.15 & 0.19 & $0.17 \pm 0.01$ \\
\hline
\end{tabular}

Table 2. Life cycle stages of P. marginatus on Jatropha $(* n=25)$.

\begin{tabular}{|c|c|c|c|c|c|c|}
\hline \multirow[t]{3}{*}{ Stage of Life cycle } & \multicolumn{3}{|c|}{ Female } & \multicolumn{3}{|c|}{ Male } \\
\hline & \multicolumn{3}{|c|}{ Duration (in days) } & \multicolumn{3}{|c|}{ Duration (in days) } \\
\hline & Min & Max & *Mean \pm SD & Min & Max & Mean \pm SD \\
\hline Incubation period & 3 & 9 & $6.80 \pm 2.0$ & 3 & 10 & $6.80 \pm 2.0$ \\
\hline Nymphal instars & & & & & & \\
\hline I & 4 & 6 & $5.32 \pm 0.6$ & 5 & 7 & $5.8 \pm 0.7$ \\
\hline II & 3 & 4 & $3.48 \pm 0.5$ & 4 & 5 & $4.5 \pm 0.5$ \\
\hline III & 7 & 11 & $8.52 \pm 1.3$ & 7 & 11 & $8.6 \pm 1.5$ \\
\hline Total nymphal period & 14 & 21 & $17.32 \pm 1.6$ & 16 & 23 & $18.9 \pm 1.3$ \\
\hline Pre pupal period & - & - & - & 2 & 3 & $2.3 \pm 0.48$ \\
\hline Pupal period & - & - & - & 4 & 5 & $4.7 \pm 0.4$ \\
\hline Pre-oviposition period & 6 & 9 & $8.28 \pm 1.02$ & - & - & - \\
\hline Oviposition period & 11 & 15 & $13.48 \pm 1.4$ & - & - & - \\
\hline Post-oviposition period & 7 & 9 & $7.64 \pm 1.0$ & - & - & - \\
\hline Adult longevity & 25 & 33 & $29.44 \pm 2.2$ & 2 & 3 & $2.2 \pm 0.4$ \\
\hline Fecundity/ female & 248 & 67 & $618.9 \pm 19$ & - & - & - \\
\hline Total life span & 42 & 63 & $53.56 \pm 3.2$ & 27 & 44 & $34.5 \pm 1.5$ \\
\hline
\end{tabular}


Veeresh Kumar et al. / J. Appl. \& Nat. Sci. 6 (2): 770 - 778 (2014)

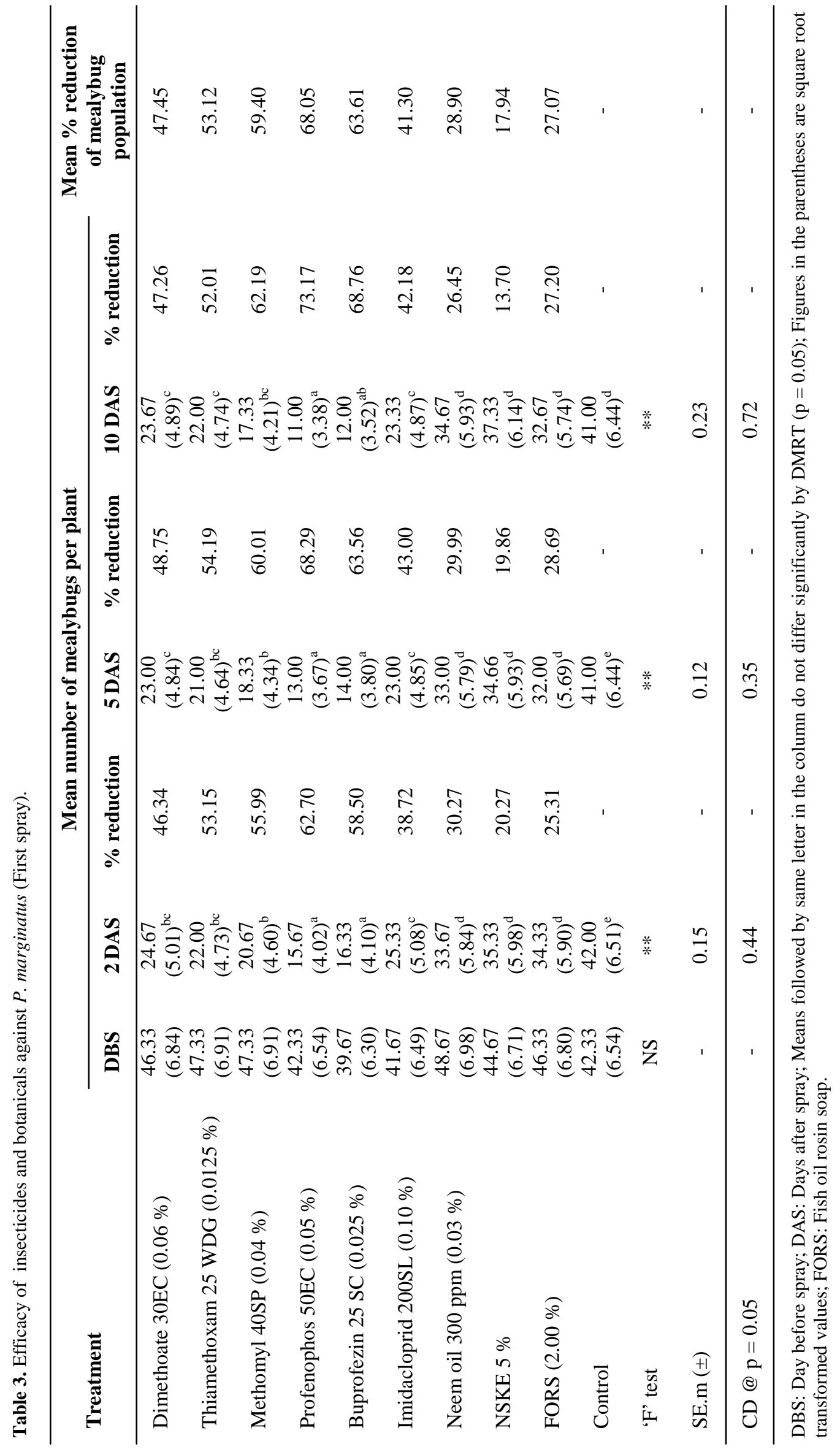




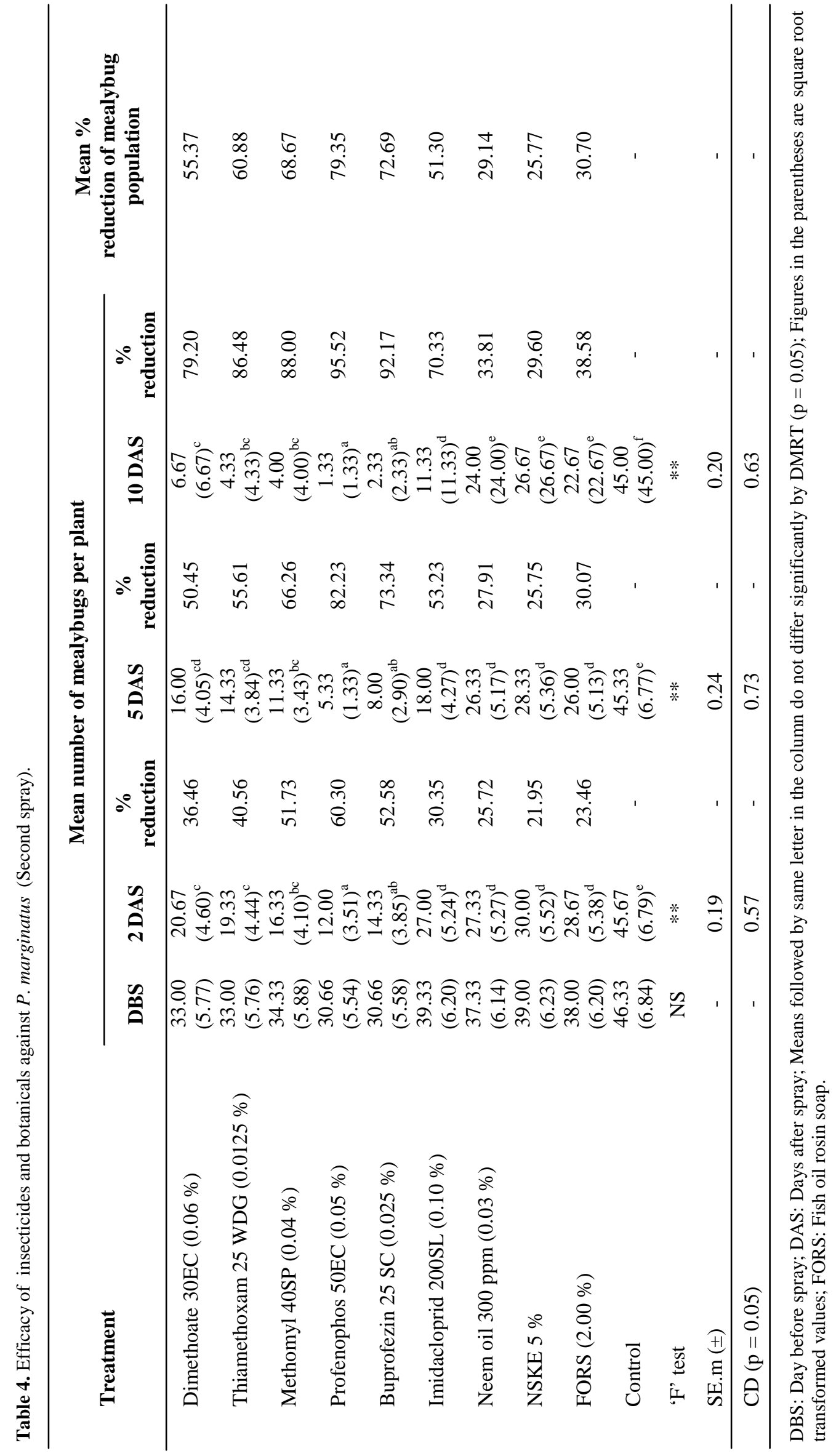


Veeresh Kumar et al. / J. Appl. \& Nat. Sci. 6 (2): 770 - 778 (2014)

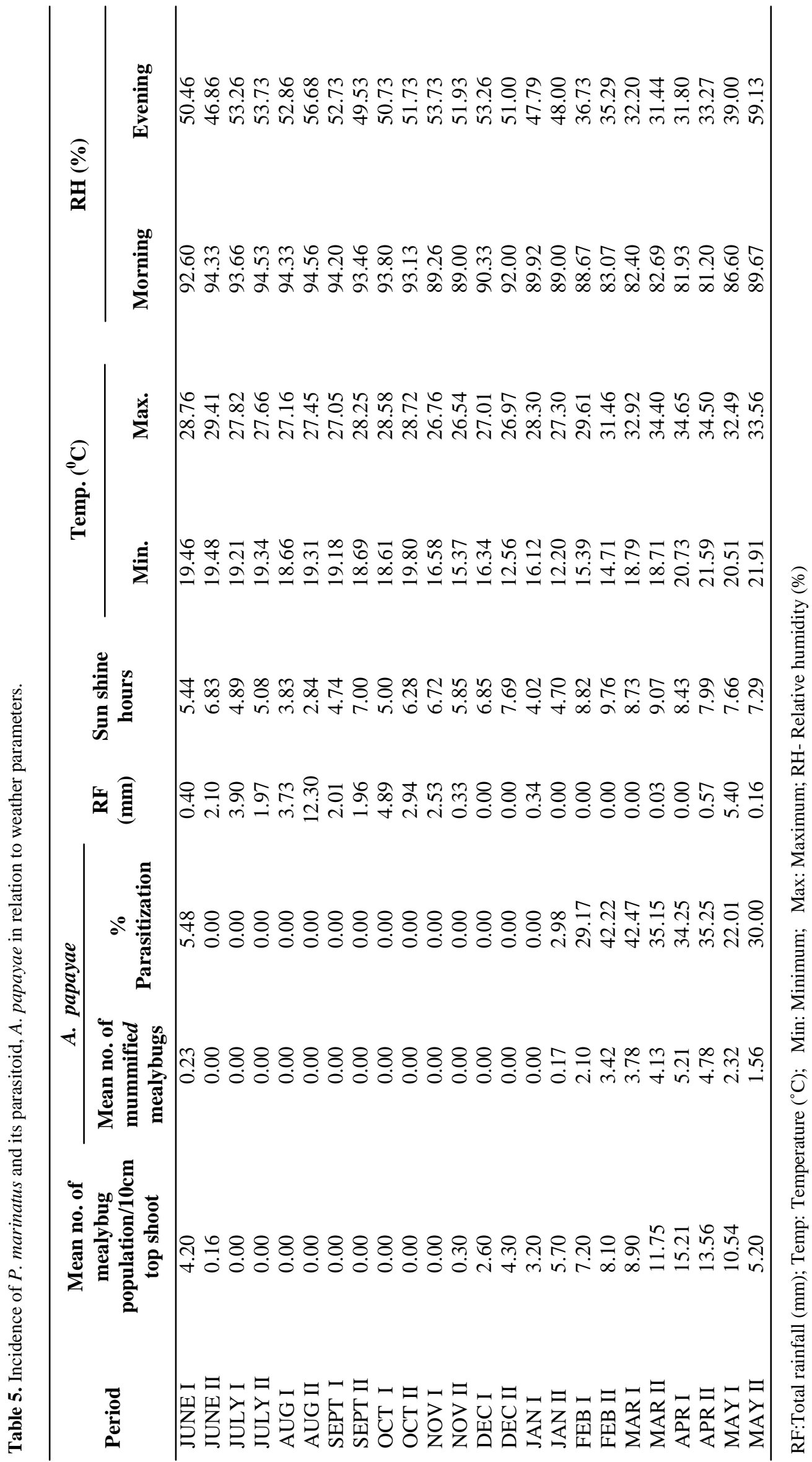




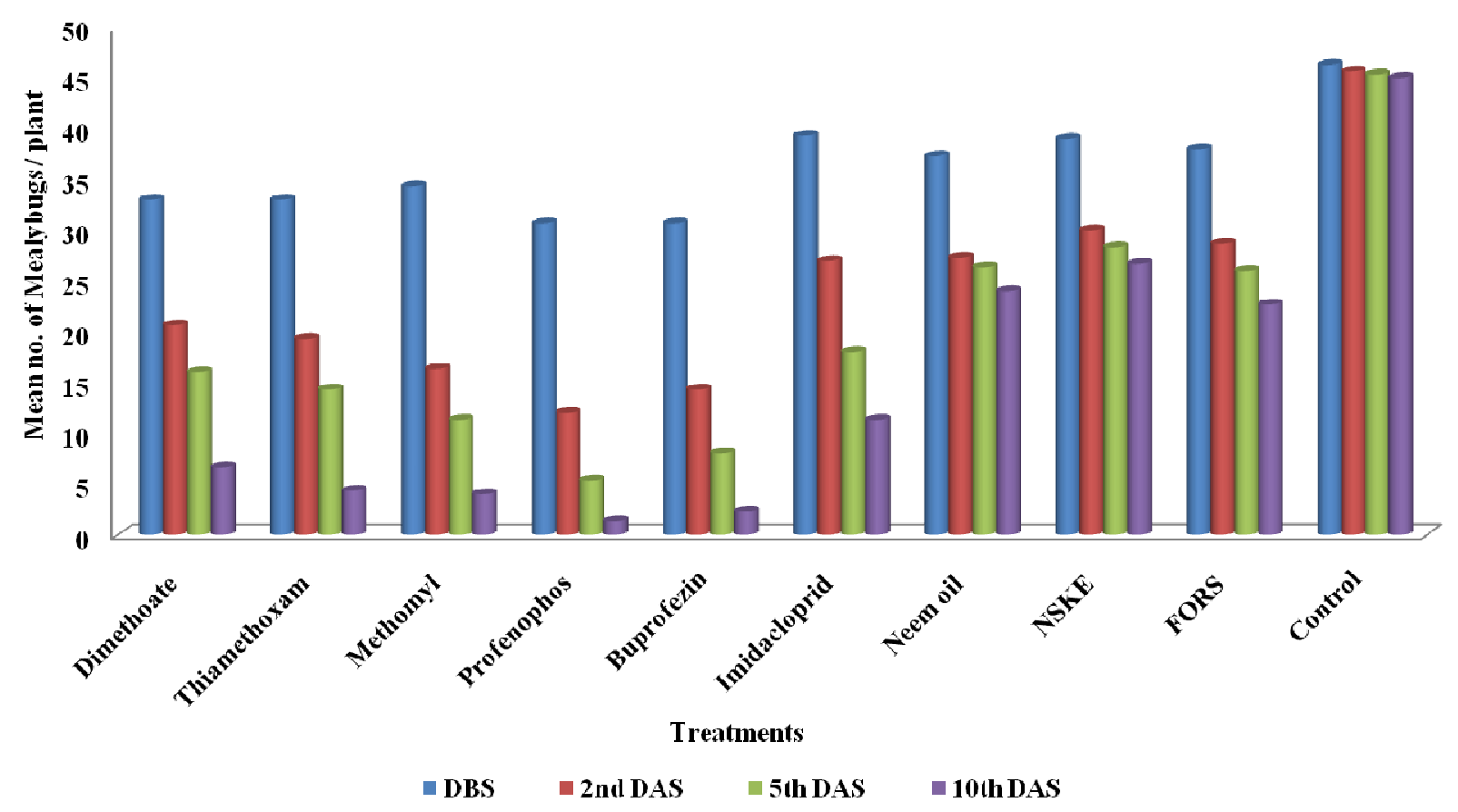

Fig. 1. Efficacy of new insecticides and botanicals against P. marginatus under glass house condition.

(2008), as they reported three nymphal instars, more or less same duration and no pupal stage in the wingless $P$. marginatus female.

Male mealybug had three nymphal instars besides pre-pupa and pupa; the mean duration of first, second and third instar was 5.8, 4.5 and 8.6 days, respectively. At the end of third nymphal instar, males produced puparia over their bodies. Pre-pupal period ranged from 2 to 3 days, with an average of 2.3 days; pupal duration ranged from 4 to 5 days, with an average of 4.7 days. The total developmental period of male nymphs ranged from 16 to 23 days, with a mean of 18.9 days. Longer nymphal duration of males compared to females was due to additional pre pupal and pupal stages. The present results are comparable to the findings of Walker et al. (2008), who reported three nymphal instars besides pupa and a winged adult stage in P. marginatus. But, the present results are contrary to the findings of Muniappan et al. (2008), as they had reported that the winged $P$. marginatus male has two nymphal stages, a pre-pupa and a pupal stage. The slight variation in the nymphal developmental time may be due to the differences in climatic conditions, particularly with respect to temperature and relative humidity. Amarasekare et al. (2008), who investigated the effect of temperature on the development of $P$. marginatus was able to complete its development between $18^{\circ} \mathrm{C}$ to $35^{\circ} \mathrm{C}$ and required $303.00 \mathrm{DD}$ and 294.10 DD to complete development of the male and the female, respectively.

In the present study, pre-oviposition, oviposition and post-oviposition periods varied from 6 to 9,11 to 15 and 7 to 9 days, with an average of $8.28 \pm 1.02$ days, $13.48 \pm 1.4$ days and $7.64 \pm 1.0$ days, respectively. The present findings are similar to the findings of Muniappan et al. (2008) and Singh and Beera (2010) who reported that egg-laying of $P$. marginatus usually occurs over the period of one to two weeks; fecundity of female mealybug ranged from 248 to 967 , with an average of $618.9 \pm 19$. The fecundity of $P$. marginatus was similar to the observations made by Walker et al. (2008) and Singh and Beera (2010), who reported that females of $P$. marginatus usually lay 100 to 600 eggs in an ovisac, in a span of one to two weeks.

The developmental period of the adult female varied from 43 to 62 days, with an average of $53.56 \pm 3.2$ days; while, male development varied between 27 to 44 days with an average of $34.5 \pm 1.5$. Similar observations were recorded by McKenzie (1967), Walker et al. (2008) and Singh and Beera (2010), as they reported that the total life cycle/developmental period was 1-2 months depending on the season.

Efficacy of insecticide molecules and botanicals against $\boldsymbol{P}$. marginatus: The studies on efficacy of insecticides revealed that the pre-treatment population of the mealybug ranged from 39.67 to 48.67 during $1^{\text {st }}$ spray and 30.66 to 39.33 during $2^{\text {nd }}$ spray (Table 3 and 4).

During $1^{\text {st }}$ spray, the lowest mealybug population was recorded in profenophos at two, five and ten DAS was $15.67,13.00$ and11.00, respectively followed by buprofezin at two (16.33), five (14.00) and ten (12.00) DAS. The highest mealybug population was observed in control. The mortality of mealybug to the insecticides in the decreasing order, according to their efficacy were profenophos $>$ buprofezin $>$ methomyl $>$ thiamethoxam $>$ dimethoate $>$ imidacloprid $>$ neem oil $>$ FORS and NSKE 5\%. During $2^{\text {nd }}$ spray, the lowest 


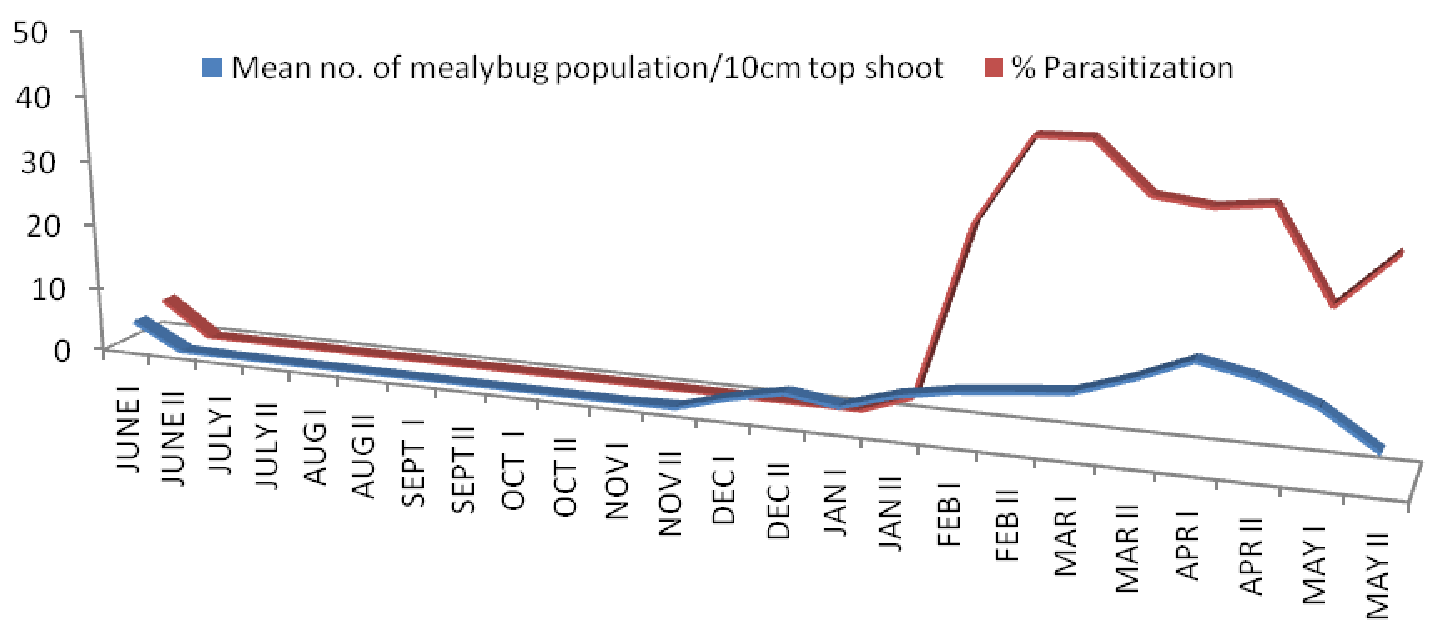

Fig. 2. Population of $P$. marginatus and its per cent parasitization.

mealybug population was recorded in profenophos at two, five and ten DAS with the mean value of 12.00 , 5.33 and 1.33 , respectively followed by buprofezin at two (14.33), five (8.00) and ten (2.33) DAS. The highest mealybug population was observed in control. The mortality of mealybug to the insecticides in the decreasing order, according to their efficacy were profenophos $>$ buprofezin $>$ methomyl $>$ thiamethoxam $>$ dimethoate $>$ imidacloprid $>$ neem oil $>$ FORS and NSKE 5\% (Fig. 1).

The perusal of literature revealed that there is little work on the efficacy of insecticides against $P$. marginatus under glass house conditions. However, the efforts have been made to compare these results with earlier work on other crops. Mahalingam et al. (2010) reported the effectiveness of profenophos @ 2 $\mathrm{ml} /$ liter on stumps immediately after pruning followed by second spray, 15 days after pruning along with stickers in controling of P. marginatus. Agarwal et al. (2009) reported three days after second spray, profenophos 50 EC recorded 93.73 per cent mortality over control and was on par with spirotetramate $12 \%+$ imidacloprid 36\% 480 SC (36+108 g a.i./ha) (85.09\% mortality) and thiodicarb 75 WP $750 \mathrm{~g}$ a.i./ha $(84.48 \%$ mortality) on cotton. Bhosle et al. (2009), have reported the yield of seed cotton was significantly highest in acephate $70 \mathrm{SP}(22.2 \mathrm{q} / \mathrm{ha})$ and profenophos 50 EC $(22.2 \mathrm{q} / \mathrm{ha})$ which gave good control of mealybugs. Balikai $(2002,2005)$ reported buprofezin $25 \mathrm{SC} @ 1125 \mathrm{ml} / \mathrm{ha}$ along with fish oil rosin soap (Meenark) at $3125 \mathrm{~g} / \mathrm{ha}$ was effective for the management of the grape vine mealybug, $M$. hirsutus. Muthukrishnan et al. (2005) had reported that buprofezin $25 \mathrm{SC} @ 1125 \mathrm{ml} / \mathrm{ha}$ sprayed thrice at 15 days interval reduced the congregation of $M$. hirsustus on grape and increased the yield.

Natural enemy complex of $\boldsymbol{P}$. marginatus: There are ten natural enemies were recorded on the mealybug. They were 3 parasitoids viz., Acerophagus papayae Noyes and Schauff, Anagyrus loecki Noyes, Pseudleptomastix mexicana Noyes and Schauff and 7 predators viz., Spalgis epius (Westwood), Cryptolaemus montrouzieri Mulsant, Brumoides suturalis (Fabricius), Cheilomenes sexmaculata (Fabricius), Scymnus coccivora Ayyar, Chilocorus sp. and Chrysoperla zastrowi Sillemi (Esben-Petersen). Among these, A. papayae found to be more effective in controlling the mealybug population.

The population of the encyrtid parasitoid, A. papayae was significant and positively correlated with $P$. marginatus population (Table 5 and Fig. 2). Peak mealybug infestation was noticed during second fortnight of January to first fortnight of June (4.2 to $15.21 / 10 \mathrm{~cm}$ top shoot). The peak infestation may be due to higher temperature that prevailed during this period, which probably helped fast multiplication of the mealybug. Further, positively correlated with maximum temperature $(r=0.91)$ and sunshine hours $(r=0.74)$. Whereas, significantly negatively correlated with morning $(\mathrm{r}=-0.90)$ and evening $(\mathrm{r}=-0.85)$ relative humidity (Table 6). However, gradually decreases as the season advanced and there was no incidence during July to November. This could be due to higher rainfall during kharif and low temperature during rabi which might have caused low rate of reproduction of the mealy bug. This closely agrees with the findings of Mani (1986), who reported positive and significant correlation of maximum temperature with mealybug population on grapevine, while the relative humidity showed negative correlation. Similar studies were made by Dhawan et al. (2009), Kumar et al. (2002) and Hanchinal et al. (2010) positive and significant correlation of maximum temperature with Maconellicoccus hirsutus, while the relative humidity showed negative correlation.

Maximum per cent parasitization was noticed during mid February to first fortnight of March (42.47\%). The present results are in accordance and conformity with the observations made by Noyes and Schauff (2003), Kauffman et al. (2001), Meyerdirk et al. (2004) and Muniappan et al. (2006), who had reported that A. papayae, A. loecki, Pseudaphycus sp. and $P$. mexicana and predator, $C$. montrouzieri Mulsant as 
Table 6. Correlation between mealy bug population and its parasitoid, Acerophagus papayae with weather parameters.

\begin{tabular}{llcccccc}
\hline Parameters & \multicolumn{1}{c}{ X1 } & $\mathbf{X 2}$ & $\mathbf{X 3}$ & $\mathbf{X 4}$ & $\mathbf{X 5}$ & $\mathbf{X 6}$ & X7 \\
\hline Parasitoid population & $0.928^{* *}$ & $0.916^{* *}$ & 0.294 & $-0.914^{* *}$ & $-0.888^{* *}$ & -0.318 & $0.741^{* *}$ \\
Mealy bug population & 1 & $0.861^{* *}$ & 0.139 & $-0.902^{* *}$ & $-0.858^{* *}$ & -0.391 & $0.693^{* *}$ \\
\hline
\end{tabular}

$\mathrm{X} 1=$ Mealy bug population; X2= Maximum Temperature; X3=Minimum Temperature; X4=Morning Relative humidity; $\mathrm{X} 5=$ Evening Relative humidity; $\mathrm{X} 6=$ Rainfall; $\mathrm{X} 7=$ Sunshine hours; ${ }^{*}$ Correlation is significant at $\mathrm{P} \leq 0.05$; ** Correlation is significant at $\mathrm{P} \leq 0.01$

effective in controlling of mealybug. Kaushalya et al. (2009), had reported that $A$. papayae recorded a higher per cent parasitism than $A$. loecki in both the open-sleeve cage $(31.0 \% \mathrm{v} / \mathrm{s} 2.3 \%)$ and the no-cage treatments $(21.4 \% \mathrm{v} / \mathrm{s} 1.6 \%)$ and caused the maximum mortality of P. marginatus. Mahalingam et al. (2010) found Spalgis epeus to be quite active and keeping the population under check in certain areas. Thangamalar et al. (2010) observed that $S$. epeus larvae devoured about 42 to 53 $(48.15 \pm 4.08)$ ovisacs and 196 to $222(210.99 \pm 10.77)$ nymphs and adults of $P$. marginatus.

\section{Conclusion}

Accurate knowledge of the insects present in an area is essential as a basis for development of integrated pest management. Thus, the present study on biology is helpful to determine the weak links in its growth stages and paved the way for its effective suppression. In addition to general examination, to detect their speed, special attention should be focused on areas where mealybugs are likely to hide, such as shoot tips, leaf bases and on the fruits. Commodities for export should preferably be grown in pest-free areas. Pre-entry quarantine inspection and treatment should be prerequisites for export. Monitoring and timely control measures can also help to reduce the pest impact to increase bio-fuel production while, biological control avenues may be fully explored.

\section{REFERENCES}

Agarwal, N; Vika, J. and Vikram, S. (2009). Evaluation of some new insecticides against mealybug, Phenacoccus solenopsis Tinsley (Hemiptera: Pseudococcidae) on cotton. Pestology, 33(6): 29-33.

Amarasekare, K.G; Chong, J.H; Epsky, N.D. and Mannion, C.M. (2008). Effect of temperature on the life history of the mealybug, Paracoccus marginatus (Hemiptera: Pseudococcidae). Journal of Economic Entomology, 101: 1798-1804.

Balikai, R.A. (2002). Bio-efficacy of buprofezin 25 EC against grape mealybug, Meconellicoccus hirsutus (Green). Pestology, 26(10): 20-23.

Balikai, R.A. (2005). Management of grape mealybug, Maconellicoccus hirsutus (Green) using insect growth regulator. Research on Crops, 6(1): 68-71.

Bhosle, B.B; Sharma, O.P; More, D.G; Bhede, B.V. and Bambawale, O.M. (2009). Management of mealybug, Phenacoccus solenopsis in rainfed cotton Gossypium hirsutum. Indian Journal Agricultural Sciences, 79(3): 199-202.

Dehgan, B. (1984). Phylogenetic significance of inter-specific hybridization in Jatropha (Euphorbiaceae). Systematic Botany, 9(4): 467-478.

Dhawan, A.K; Singh. K; Aneja, A. and Saini, S. (2009). Distribution of mealy bug, Phenacoccus solenopsis Tinsley in cotton with relation to weather factors in south-western districts of Punjab. Journal of Entomological Research, 33(1): 59-63.

Hanchinal, S.G; Patil, B.V; Bheemanna, M. and Hosamani, A.C. (2010). Population dynamics of mealy bug, Phenacoccus solenopsis Tinsley and its natural enemies on Bt cotton. Karnataka Journal of Agricultural Sciences, 23(1): 137-139.

Kaushalya, G; Amarasekare, A; Catharine, M; Mannion, B. and Nancy, D. (2009). Efficiency and establishment of three introduced parasitoids of the mealybug, Paracoccus marginatus (Hemiptera: Pseudococcidae). Biological Control, 51: 91-95.

Kauffman, W.C; Myerdirk, D.E; Miller, D; Schauff, M; Hernandez, H.G. and Jimenez, J.A.V. (2001). Papaya mealybug biological control in Puerto Rico and Dominican Republic. The ESA 2001 Annual Meeting - 2001: An Entomological Odyssey of ESA.

Kumar, T.S; Sheela, M.S. and Anoop, S. (2002). Occurrence of red cottonbug, Dysdercus cingulatus (Fb.) and white mealybug, Ferrisia virgata (Ckll.) on Kurumthotti, Sida rhombifolia L. (Malvaceae) - a new report. Insect Environment, 8(4): 177.

Lynne, N.C; John, J. and Mchugh, J.R. (2005). Pest management strategic plan for papaya production in Hawaii. Workshop Summary December 2.

Mahalingam, C.A; Murugesh, K.A; Mohanraj, P. and Shanmugam, R. (2010). Papaya mealybug, Paracoccus marginatus - A new pest on mulberry, Morus spp., in Karnataka. Journal of Agricultural Sciences, 23(1): 182 -183 .

Mani, M. 1986. Distribution, bioecology and management of the grape mealybug Maconellicoccus hirsutus (Green) with a special reference to its enemies. Ph.D. thesis, University of Agricultural Sciences, Bangalore.

Mckenzie, H.L. (1967). Mealybugs of California with taxonomy, biology and control of North American species (Homoptera: Coccoidea: Pseudococcidae). University of California Press, Berkeley, Los Angeles.

Meyerdirka, D.E; Muniappan, R; Warkentin, R; Bamba, A.J. and Reddy, G.V.P. (2004). Biological control of the papaya mealybug, Paracoccus marginatus (Hemiptera: Pseudococcidae) in Guam. Plant Protection Quarterly, 19: $110-114$.

Miller, D.R. and Miller, G.L. (2002). Redescription of Paracoccus marginatus Williams and Granara De Willink (Hemiptera: Coccoidea: Pseudococcidae) including descriptions of the immature stages and adult male. Proceedings of the Entomological Society, Washington. 104:123.

Muniappan, R; Meyerdirk, D.E; Sengebau, F.M; Erringer, 
D.B. and Reddy, G.V.P. (2006). Classical biological control of the Papaya mealybug, Paracoccus marginatus (Hemiptera: Pseudococcidae) in the Republic of Palau. Florida Entomologist, 89(2): 212-217.

Muniappan, R; Shepard, B.M; Watson, G.W; Carner, G.R; Sartiami, D.A; Rauf. and Hammig, M.D. (2008). First report of the papaya mealybug, Paracoccus marginatus (Hemiptera: Pseudococcidae) in Indonesia and India. Journal of Agricultural Urban and Entomology, 25(1): $37-40$.

Muthukrishnan, N; Manohan, T; Thirumalai, T. and Anbu, S. (2005). Evaluation of buprofezin for the management of grape mealybug, Maconellicoccus hirsutus (Green). Journal of Entomological Research, 29: 339-344.

Noyes, J.S. and Schauff, M.E. (2003). New encyrtidae (Hymenopetera) from papaya mealybug (Paracoccus Marginatus William and Granara de Willink) (Hemiptera: Sternorrhyncha: Pseudococcidae). Proceedings of Entomological Society of Washington, 105: 185

Pant, K.S; Khosla, V; Dinesh kumar and Sumeet, G. (2006). Seed oil content variation in Jatropha curcas L. in different altitudinal ranges and site conditions in H.P., India. Lyonia- A Journal of Ecology and Application, 11(2):31-34.

Regupathy, A. and Ayyasamy, R. (2009). Need for generating baseline data for monitoring insecticide resistance in new invasive mealybug Paracoccus marginatus Williams and Granara de Willink (Insecta: Hemiptera: Pseudococcidae), the key pest of papaya and biofuel crop, Jatropha curcas. Resistance Pest Management, 19 (1): 39-42.

Regupathy, A. and Ayyasamy, R. (2010). Honey bee friendly pest management in biofuel, Jatropha plantation. National Symposium on "Non-Chemical Insect Pest Management. Loyala College, Chennai. 178-188.

Singh, R.N. and Beera, S. (2010). Biology of papaya mealybug and its biological control in sericulture. Indian Silk, 49 (4): 6-7.

Thangamalar, A; Subramanian, S. and Mahalingam, C.A. (2010). Bionomics of papaya mealybug, Paracoccus marginatus and its predator Spalgis epius in mulberry ecosystem. Karnataka Journal of Agricultural Sciences, 23:39-41.

Veereshkumar and Ashok Kumar, C.T. (2013). Insect fauna and their occurrence on Jatropha curcas L. Mysore Journal of Agricultural Sciences, 47: 572-578.

Walker, A; Hoy, M. and Meyerdirk, D. (2008). Papaya mealybug, Paracoccus marginatus Williams and Granara de Willink (Insecta: Hemiptera: Pseudococcidae), Institute of Food and Agricultural Sciences, University of Florida, http://creatures.ifas.ufl.edu. 